\title{
The Relationship between Explicit Teaching of Grammatical Structures and Iranian High School Students' Performance in Reading Comprehension
}

\author{
Akbar Azizifar ${ }^{1}$, Habib Gowhary ${ }^{1} \&$ Alizaman Fatahi ${ }^{1}$ \\ ${ }^{1}$ Department of English Language Teaching, Islamic Azad University, Ilam Branch, Ilam, Iran \\ Correspondence: Akbar Azizifar, Department of English Language Teaching, Islamic Azad University, Ilam Branch, \\ Ilam, Iran. E-mail: akb1354@yahoo.com
}

Received: January 16, 2012

Accepted: March 10, 2015

Online Published: March 12, 2015

doi:10.5430/elr.v4n1p22

URL: http://dx.doi.org/10.5430/elr.v4n1p22

\begin{abstract}
This study examines the relationships between explicit teaching of grammatical structures and reading comprehension. The significance of this study lies in the possibility that knowledge of text structure may create connections among the disciplines which could enhance understanding of content and promote thinking and reading comprehension abilities. After administering a standardized reading comprehension test, a group of 64 high school students were selected from a total population of 84. The selected subjects were randomaly assigned to experimental and control groups. For the experimental group, the researcher held a treatment which lasted for 4 weeks, two 90 minute sessions per week. During the experiment both groups had the same instructor, curriculum, and schedule of instruction, except that in control group the students had conventional learning, that is they worked just with the reading passages without any explicit instruction or without any awareness- by being undelined - about the types of structures which were the target structure of the researcher- adjective clauses, gerunds, and infinitives-, while for the experimental group, they received explicit instruction and awareness about the types of structures which were the target structure of the researcher. At the end of the study, the obtained scores on the pre- and post-tests were analyzed through different statistical procedures. The results showed that being aware about sentence structures and the explicit teaching of grammatical structures had a significant effect on improving Iranian high school students' reading comprehension performance. The results, also indicated that significant relationships exist among the variables of sentence-structure recognition and reading comprehension. The associations support the theory that students may use sentence structure to improve thinking and reading comprehension processes. This association provides educators with a potentially powerful way to structure instruction.
\end{abstract}

Keywords: Sentence-structure, Awareness, Reading comprehension, Consciousness raising, Input enhancement

\section{Introduction}

Reading for full comprehension and learning is a special type of reading, which needs a different type of processing in terms of focusing attention, information encoding and retrieval than reading for enjoyment or reading for general information.

Sentence-structure knowledge (awareness) helps a reader to see relations between ideas, including relationships between main ideas and details and also relations among every sentence component parts in order to have a better analysis of the text and sentences and concequently a better understanding and comprehending of the text and sentences.

According to Mandler \& Johnson, in both L1 and ESL, students who have been taught how to identify text structure and use this knowledge to guide their reading process have showed better comprehension and recall of information than readers lacking such knowledge (Mandler \& Johnson, 1977). Students who are reading texts need to work actively at finding and using appropriate cues in the texts in order to enhance their understanding of them.

Research has indicated that understanding how a passage is structured is an important factor in reading comprehension. (Mandler \& Johnson, 1977; Meyer, 1979, 1982; Meyer, Brandt, \& Bluth, 1980). More specifically, it has been proved that readers who are able to identify sentence structures as well as paragraph-level relationships of a passage are better able to understand the passage than those readers who remember only a collection of details 
(Meyer, 1985). Of particular interest in the present study is the comprehension of some grammatical structures, which are interpretable only through relationships that are presupposed in the text.

It's time to say something about another important dimension of the present study which is the explicit teaching of grammar by the teacher for the Experimental group. It's better to begin with this question: What is the role of grammar instruction in language teaching?

The grammar translation method, the audiolingual method, the cognitive code method, the comprehension method and the communicative method all view the role that grammar should play in language teaching with slight variations. Very early in the days of the communicative competence movement, Canale \& Swain (1980) proposed that grammatical competence was an integral part of communicative competence. Some language teachers moving into the communicative era may have reacted too quickly in assuming that grammar was not a significant part of language teaching and thus ignored its role in the classroom. Fotos (1994) states that the recent discussion of the role that grammar plays in language teaching:

"presents a dilemma for many teachers who have become committed to the use of communicative approaches to language learning, wherein learners are given a rich variety of comprehensible input, and teacher-fronted grammar instruction is generally omitted" (Fotos 1994, p.323).

Language teaching should place grammar back into the curriculum through a careful evaluation of the variables which influence learning and through appropriate techniques to make language learning enjoyable.

\section{Sentence Structure Awareness}

If awareness of text organization is essential for text comprehension (Meyer, Brandt, \& Bluth, 1981), it follows that the presence of some grammatical structures in text should facilitate the instantiation of textual schemata (Kieras, 1985), help to direct readers' attention to important text information (Lorch \& Lorch, 1986), and help in checking information in memory (Spyridakis \& Standal, 1987). Typical research studies addressing the question of whether explicit text signaling facilitates comprehension compare the effect on comprehension of reading intact texts with texts from which conjunctions have been removed. Results have been controversial. Some studies lead to the conclusion that comprehension is not affected, whereas others suggest that awareness of grammatical structures facilitate comprehension under some reader and text conditions. Spyridakis and Standal (1987) found that signaling facilitated comprehension of expository texts by college students when passages were "neither too easy, nor too difficult" (Standal, 1987, p. 285).

Skilled and less skilled readers have been shown to differ in the degree to which they infer logical relations in text (Bridge\& Winograd, 1982; Evans \& Ballance, 1980; Geva, 1986a; Geva \& Ryan, 1985; Irwin, 1980). Meyer, Brandt, and Bluth (1981) showed that connectives facilitated recall among ninth-grade students who were poor comprehenders but did not among skilled readers.

The schema theory proposed by Bartlett (1932); stresses the importance of background knowledge and knowledge of structures (schemas) for text comprehension. Richards (1989) and also Brown and Yule (1983a) discuss different types of knowledge schemas such as frames and scripts. Richards defines scripts as a specific variety of knowledge schemas that comprise situation-specific knowledge about the goals, participants and procedures in real-life situations.

Goodman and Niles' (1970) psycholinguistic view points out that the reader interacts with the text in the form of a guessing game. The aim of this guessing game is to re-construct the message that has been encoded by its author in the form of a graphic display. For this purpose readers create meaning in a cyclical process by predicting, testing, confirming or revising their own initial predictions. A text does not carry meaning by itself; it becomes its meaning from the readers' actualization of their own pre-knowledge including their knowledge of various grammatical structures which are used within the texts.

When students process a simple sentence, they mainly use word associations. Syntax merely helps them corroborate the associations. But when the associations are ambiguous and/or the syntax is complex, students must have a good understanding of syntax in order to work out how each word fits into the sentence structure and, ultimately, comprehend the sentence.

Students are more likely to encounter ambiguity and complexity in reading than in speech; the grammatical structures used in written text are more varied and complex than those used in casual conversation. Thus, students must learn the rules of formal syntax in order to become fluent readers. 


\section{Research methodology}

\subsection{Methodology}

As it was stated before, the purpose of the present study is to investigate the relationship between sentence structure awareness and performance in reading comprehension. What follows is a description of the methodology used in the study.

\subsubsection{Participants}

The participants were 84 third- grade high school students at Bagerololom high school in Ilam. A Michigan test was used to screen the required number of students who were supposed to take part in the main part of the study procedures. Among 84 students taking the Michigan test, 64 students were qualified to be classified into the control and experimental group because their scores were something between1 SD above and1 SD below the mean scores of all the subjects.

\subsubsection{Materials}

The materials used in this study were two texts from English Book 3 consisting of passages in which the researcher's target structures were used deliberately in order to convey a message. The researcher used passages that were more likely to contain large numbers of adjective clauses, gerunds and infinitives.

A Michigan test (1997 version) of language proficiency was given to the subjects in order to come up with a homogeneous number of subjects. The test consisted of three sections: grammar (40 questions), vocabulary (40 questions), and reading comprehension (20 questions).

Out of 84 participants, 64 participants were considered to be homogeneous.

\subsection{Design}

The statistical procedure used in the study was a series of Matched T- tests and Independendent -Sample T- tests.

The Design of this study was a: Pre-test Post-test Control Group Design:

\section{G1 T1 X T2}

G2 T1 T2

$\mathrm{G} 1=$ Experimental group, $\mathrm{G} 2=$ Control group, $\mathrm{T} 1=$ Pretest, $\mathrm{T} 2=$ Posttest, and $\mathrm{X}=$ Treatment

As it has been mentioned before, on the basis of the results of the proficiency test - the Michigan test- 64 students whose sores were between 25 and 49 ( 1 SD above and 1 SD below the mean) were chosen as the key informants. That is, scores which were very high or too low on the test were discarded. The selected subjects were randomaly assigned to two groups of experimental and control. For the experimental group the researcher held a treatment which lasted for (4) weeks, two sessions a week and each session lasted for 90 minutes. During the experiment, both groups had the same instructor, curriculum, and schedule of instruction, except that in control group the students had conventional learning; that is they worked just with the reading passages without any explicit instruction or without any awareness- by being undelined- about the types of structures which were the target structure of the researcher adjective clauses, gerunds, and infinitives-, while for the experimental group, they got explicit instruction and awareness- by being undelined - about the researcher intended structures.

The description of the design for the assessment of the variables at hand is as follow:

The research hypothesis:

There is no relationship between explicit teaching of grammatical structures and Iranian high school students' performance in reading comprehension.

The level of significance for this two- tailed test was 0.05 , the dependent variable was reading comprehension, while the independent variable was sentence structure awareness.

\subsection{Procedures}

The Michigan test of language proficiency was given to the participants. In order to come up with a homogeneous number of subjects the exam papers were scored and the scores were scattered over a normal distribution diagram with the mean of $\mathbf{3 7}$ and the standard deviation of around 12. After this, 64 out of 98 subjects were classified into Control (32) and Experimental (32) group. 
Table 1. Frequency Table of Statistics

\begin{tabular}{lllll}
\hline & $\begin{array}{l}\text { Pre-test } \\
\text { Experimental }\end{array}$ & $\begin{array}{l}\text { Post-test } \\
\text { Experimental }\end{array}$ & $\begin{array}{l}\text { Pre-test } \\
\text { Control }\end{array}$ & Post-test Control \\
\hline $\mathrm{N} \mathrm{Valid}$ & 32 & 32 & 32 & 32 \\
Missing & 0 & 0 & 0 & 0 \\
Mean & 10.0000 & 12.1875 & 9.9063 & 9.8750 \\
Std. Error of mean & .48775 & .63092 & .45649 & .56395 \\
Median & 10.0000 & 11.0000 & 10.0000 & 10.5000 \\
Mode & 11.00 & 9.00 & $8.00 \mathrm{a}$ & $11.00 \mathrm{a}$ \\
Std. Deviation & 2.75915 & 3.56902 & 2.58231 & 3.19021 \\
Variance & 7.61290 & 12.73790 & 6.66835 & 10.17742 \\
Range & 12.00 & 12.00 & 11.00 & 12.00 \\
Minimum & 4.00 & 7.00 & 5.00 & 4.00 \\
Maximum & 16.00 & 19.00 & 16.00 & 16.00 \\
Sum & 320.00 & 390.00 & 317.00 & 316.00 \\
\hline
\end{tabular}

a. Multiple model exist. The smallest value is shown

\subsection{Data collection and analysis procedure}

The effectiveness of a metacognitive approach to teaching adjective clauses, gerunds and infinitives as grammatical structures and their effectiveness on the reading comprehension abilities of readers was the researcher's main aim, so in order to come into this aim, the researcher gave a kind of pretest in order to know if the two groups were at the same level, then experimental subjects received grammatical-structure awareness training in order to be able to analysis, monitor and understand the specific grammatical structures which were used in the texts and passages and the understanding of them had a crucial role in the understanding of the texts and passages.

After the treatment the researcher collected the required data by giving a post- test to the two groups, and after that by using a series of Independent- Sample T-tests the mean of the two groups were compared with each other in order to know: was the difference between the mean of the two groups is so meaningful that the researchers can claim that this gain of the experimental group is just because of the study variable-grammatical structure awareness- or not?

The descriptive statistics is showed in table 2. This table is one more indication of the students' performance on pretest. It shows the calculation for the mean, standard deviation, and variance for both sets of scores.

Table 2. Descriptive Statistics (pretest for both groups)

\begin{tabular}{lccc}
\hline Group & $\mathrm{X}$ & $\mathrm{S}$ & $\mathrm{V}$ \\
\hline Experimental & 10.00 & 2.75 & 7.61 \\
Control & 9.90 & 2.58 & 6.66
\end{tabular}

Table 3. Independent T-test Experimental VS. Control Group on Pretest

\begin{tabular}{lccc}
\hline Observed t & Degree of freedom & 2-tail $\mathrm{p}$. & Critical $\mathrm{t}$ \\
\hline 0.14 & 62 & 0.05 & 2
\end{tabular}

The table indicates that our two samples had, though not exactly, the same dispersion of scores which seemed to be suitable for our purpose in this research. Next an independent t-test was calculated to verify the pretest results on both groups. (table 3). It showed no significant difference on the pretest between the performance of the experimental and control group prior to training.

As the table shows the value of the calculated $t$ is (0.14) which is less than the value of the critical (2) at 0.05 level of probability. Therfore, the two groups have little or almost no differences.

The treatment which the experimental group received, was related to explicit instruction of some specific grammatical structures (here adjective clauses, gerunds and infinitives), and also the underlining of these structures in order for the students to be aware of these structures within passages. After 8 sessions which lasted 4 weeks, the 
same reading comprehension test with the same nature and characteristics with respect to the organization, administration, and scoring as the one in the pretest was conducted with the aim of statistically determining whether there was any significant improvement in the reading comprehension ability of the participants in the experimental group. This was done through calculating and comparing the t-test of the groups. Complete data analysis is given in the next part (results).

As it has been indicated above after four weeks of treatment in which the experimental subjects were instructed explicitly about the the kinds of structures which were going to be used in the texts and passages of post-test and the understanding of them was going to have a crucial rule in the understanding of the texts and passages, and also the underlining of the above structures in the texts and passages during the treatment phase, after two weeks the post-test had been held and then a series of Independent- Sample T-tests in which the mean of the two groups had been compared had been used (see the next part).

\section{Results}

As stated earlier, the purpose of the study was to investigate the relationship between explicit teaching of grammatical structures and Iranian high school students' performance in reading comprehension. To investigate this claimed link the following question was raised, and the following hypothesis was put forward.

Is there any relationship between explicit teaching of grammatical structures and Iranian high school students' performance in reading comprehension?

Restatment of the Hypothesis:

There is no relationship between explicit teaching of grammatical structures and Iranian high school students' performance in reading comprehension.

In order to test the above stated hypothesis, a series of Independent- Sample T-tests and matched T-tests were utilized. The step- by-step procedure is detailed here.

This table presents the calculations for mean, standard deviation, and variance for both sets of scores on posttest.

An independent T-test also is calculated to compare the experimental and control group mean scores on the posttest.

The t-observed value (3.12) at (62) degree of freedom and at the probability level of 0.05 is greater than the critical value of $t(2)$. Thus the null hypothesis is rejected, this means that experimental group $(X=12.18)$ outperformed the control group $(X=9.87)$ on the posttest.

As the results of the study indicated, explicit teaching and students awareness of grammatical structures had a significant effect on the improvement of the Iranian high school students' perfotmance in reading comprehension. The findings of this study suggest that explicit teaching and students awareness of grammatical structures play an important role on the improvement of the subjects reading comprehension ability. Therfore more emphasis should be put on the readers' explicit instruction and awareness.

Having compared the pretest and posttest scores of both groups, we found an increase in the posttest mean score of experimental group which demonstrated empirically that explicit teaching and students awareness of grammatical structures play an important role on the improvement of the subjects reading comprehension ability.

In conclusion, there is some evidence that explicit teaching and students awareness of grammatical structures can provide positive effects on reading comprehension ability (see tables $4 \& 5$ ).

Table 4. Descriptive Statistics (Posttest)

\begin{tabular}{lccc}
\hline Group & $\mathrm{X}$ & $\mathrm{S}$ & $\mathrm{V}$ \\
\hline Experimental & 12.18 & 3.56 & 12.73 \\
Control & 9.87 & 3.19 & 10.17 \\
\hline
\end{tabular}

Table 5. Experimental VS. Control Group on Posttest

\begin{tabular}{lccc}
\hline Observed t & Degree of freedom & 2-tail p. & Critical t \\
\hline 3.12 & 62 & 0.05 & 2 \\
\hline
\end{tabular}




\section{Discussion}

The results of the hypothesis of the present study demonstrated a positive relationship between sentence- structure awareness and reading comprehension ability of the subjects, meaning that experimental group students scores of both the pretest and post test had changed significantly due to explicit instruction during treatment and also due to experimental group students awareness of the kind of specific grammatical structures(gerunds, infinitives, and adjective clauses) used in texts, so we rejected the null hypothesis and came into an alternative hypothesis which said that there is a posetive relationship between sentence- structure awareness and reading comprehension ability of the subjects .

These findings are in keeping with Mandler \& Johnson, (1977) and Meyer, (1979) who claimed that In both L1 and ESL, students who have been taught how to identify text structure and use this knowledge to guide their reading process have showed better comprehension and recall of information than readers lacking such knowledge.

Students who are reading texts need to work actively at finding and using appropriate cues in the texts in order to enhance their understanding of them.

Research has indicated that understanding how a passage is structured is an important factor in reading comprehension. (Mandler \& Johnson, 1977; Meyer, 1979, 1982; Meyer, Brandt, \& Bluth, 1980.). More specifically, These findings are in keeping with this claim that readers who are able to identify sentence structures as well as paragraph-level relationships of a passage are better able to understand the passage than those readers who remember only a collection of details (Meyer, 1985 ).

\section{Conclusion}

The present research was an attempt to investigate the relationship between sentence- structure awareness and Iranian high school students' performance in reading comprehension. One research question was put forward as follow:

Is there any relationship between explicit teaching of grammatical structures and Iranian high school students performance in reading comprehension?

After choosing 84 high school students at Bagerololom school in Ilam who were studying at third grade, a Michigan test was used to screen the required number of students who were supposed to take part in the main part of the thesis procedures. Among 84 students taking the Michigan test, 64 students were qualified to be classified into the control and experimental group because their score was something between $1 \mathrm{SD}$ above and1 SD below the mean score of all the participants.

Then the participants got a kind of pretest in which they answered 20 multiple-choice reading comprehension items from two reading texts within which the researcher's intended grammatical structures (gerunds, infinitives, and adjective clauses) were used profoundly. The purpose of this was to know if the two groups were at the same level, then experimental subjects received grammatical- structure awareness training in order to be able to analyse, monitor and understand the intended grammatical structures which were used in the texts and passages and the understanding of them had a crucial role in the understanding of the texts and passages. Subjects in control group received conventional classroom reading activities without any treatment.

As has been mentioned above, the materials which were used in this study were two texts from Book Three and the texts themselves were consisted of passages in which the intended grammatical structures were used in a deliberate fashion in order to convey a message. The researcher used passages that were more likely to contain large numbers of adjective clauses, gerunds and infinitives.

After four weeks of treatment the post-test had been held and then the observed value of 3.12 was found to be larger than the most probable value found for 62 degree of freedom. Indeed the results showed a positive relationship between sentence structure awareness and reading comprehension ability.

\subsection{Pedagogical Implications}

The results of the present study have implications for second language pedagogy in different areas, including second language teaching. The present study represents a research project which investigated the effect of raising general metacognitive awareness of language grammatical structures on student achievement in reading comprehension. The study addressed issues raised in the literature: for example, (1) whether there is any empirical evidence to the claim that conscious awareness of language grammatical structures correlates with greater reading comprehension ability, (2) whether students actually profit from it. 
In this study it was showed that strategy training (here being aware of grammatical structures) is needed to transform less successful readers into more proficient ones and to enhance the already steady progress of good strategy users.

However, the success of strategy training as measured by the researcher is not as great as one might suspect.

From a pedagogical perspective, we can ask, how learners' attention might be directed toward formal features of the input so that they process them. That is, how can learners be directed both to make meaning and to make form-meaning connections? A type of grammatical instruction called "processing instruction" investigates the connection between input processing, comprehending input, and building linguistic systems. The research carried out to date, summarized in VanPatten (1996), consistently reports the benefits of grammatical instruction aimed at having learners attend to formal features of the input provided they attach meaning to the form (Cadierno, 1995; Cheng, 1995; VanPatten \& Cadierno, 1993; VanPatten \& Sanz, 1995). In these studies, learners not only gain in their ability to comprehend grammatical form during input processing, but they also gain in their ability to use the form in output. Both theory and pedagogy have something to gain by a continued investigation of how learners attend to input data.

\subsection{Suggestions for Further Research and Investigation}

The study can be replicated in the following ways:

The present study focused only on adjective clauses, gerunds, and infinitives. Other studies of the same type can be done developing the scope of the research into other types of grammatical studies.

More 'planned focus-on-form' research, which targets other additional grammatical features over longer periods of time for instructional treatments, is needed in order to further our understanding of how focus on- form can be implemented in the classroom.

Replications of this study using a larger sample size, additional levels of language ability, lengthier tasks/tests and collecting additional data on student strategy use through think-aloud protocols or strategy-use questionnaires will be needed in order to shed light on the potential currency of the trends detected here.

\subsection{Limitations of the study}

As it is common with every study this study had its own limitations.Grammar teaching was boring for the students, so students of experimental group were not very interested in the classes.

Another problem of this study was the selection of some grammatical structures among a lot of structures in English language ,because the researcher didn't have any kind of specific criteria in advance.At last those structure in which the subjects had difficulties with them in the general proficiency test-the Michigan Test-were selected.

Another problem is that we are in need of intervention studies in order to determine whether development of text structure knowledge results in long-lasting improvements in comprehension because it is felt that students would lose their knowledge of sentence structures by the passing of time.

A further limitation is that it was not possible to remunerate the students for their participation in this research experiment. As it has been mentioned lack of motivation may also have negatively influenced the results of the experiment.

\section{References}

Bartlett, F.C. (1932). Remembering: A study in experimental and social psychology. Cambridge: Cambridge University Press.

Brown, G., \& G. Yule. (1983a). Discourse analysis. Cambridge: Cambridge University Press. http://dx.doi.org/10.1017/CBO9780511805226

Bridge, C. A., \& Winograd, P. I. (1982). Reader's awareness of cohesive relationships during cloze comprehension. Journal of Reading Behavior, 14, 299-312.

Canale, M., \& Swain, M. (1980). Theoretical bases of communicative approaches to second language teaching and testing. Applied Linguistics: 1, 1, 1-47. http://dx.doi.org/10.1093/applin/1.1.1

Evans, R., \& Ballance, C. (1980). A comparison of sentence connective recall by two populations of readers. Journal of Educational Research, 73, 324-329. http://dx.doi.org/10.1080/00220671.1980.10885260

Fotos, S. (1994). Integrating grammar instruction and communicative language use through grammar consciousness-raising tasks. TESOL Quarterly, Vol 28, No 2. http://dx.doi.org/10.2307/3587436 
Geva, E. (1986a ). Knowledge of conjunctions and its role in comprehension. Final Report submitted to the Social Sciences and Humanities Research Council of Canada (Contract No. 410-83-1230). Toronto: Ontario Institute for Studies in Education.

Geva, E., \& Ryan, E. B. (1985). Use of conjunctions in expository texts by skilled and less skilled readers. Journal of Reading Behavior, 17, 331-346.

Goodman, K., \& Niles, O. (1970). Reading process and program. USA: National Council of Teachers of English .

Irwin, W. J. (1980). The effects of explicitness and clause order on the comprehension of reversible causal relationships. Reading Research Quarterly, 15, 477-488. http://dx.doi.org/10.2307/747275

Kieras, D. E. (1985). Thematic processes in the comprehension of technical prose. In B. K. Britton \& J. B. Black (Eds.), Understanding expository text (pp. 89-107). Hillsdale, NJ: Lawrence Erlbaum.

Lorch, R. A. F., \& Lorch; E. P. (1986). On-line processing of summary and importance signals in reading. Discourse Processes, 9, 489-496. http://dx.doi.org/10.1080/01638538609544654

Mandler, J. M., \& Johnson, M. S. (1977). Remembrance of things parsed: Story structure and recall. Cognitive Psychology, 9,pp. 111-151. http://dx.doi.org/10.1016/0010-0285(77)90006-8

Meyer, B. J. F. (1979). Organizational patterns in prose and their use in reading. In M. L. Kamil \& A. J. Moe (Eds.), Reading research: Studies and applications (pp. 109-117). Clemson, SC: National Reading Conference.

Meyer, B. J. F., Brandt, D. M., \& Bluth, G. J. (1980). Use of the top-level structure in text: Key for reading comprehension of ninth-grade students. Reading Research Quarterly, 16, pp. 72-103. http://dx.doi.org/10.2307/747349

Meyer, B. J. F., Brandt, D. N., \& Bluth, G. J. (1981). Use of author's textual schema: Key for ninth graders' comprehension. Reading Research Quarterly, 15, 72-103.

Meyer, B. J. F. (1982). Reading research and the composition teacher: The importance of plans. College Composition and Communications, 33, 37-49. http://dx.doi.org/10.2307/357843

Meyer, B. J. F. (1985). Prose analysis: Purposes, procedures, and problems. In B. K. Britton \& J. Black (Eds.), Analyzing and understanding expository text (pp. 269-304). Hillsdale, NJ: Erlbaum.

Richards, J.(1989). Profile of an effective L2 reading teacher. Prospect,4(2) 3-29 .

Spyriadakis, J. H., \& Standal, T. C. (1987). Signals in expository prose: Effects on reading. Reading Research Quarterly, 22, 285-298. http://dx.doi.org/10.2307/747969 